\section{BASEM: leadership in sport and exercise medicine despite our uncertain times}

\author{
Robin Chatterjee $\bullet^{1,2,3}$ Polly Baker $^{4}$
}

Timeline: week 4 of UK lockdown. In these unprecedented times, we maintain a semblance of normalcy by continuing to provide the high-quality education you have become used to from the British Journal of Sports Medicine (BJSM). We are proud to present the British Association of Sport and Exercise Medicine (BASEM) issue for 2020-the 54th year of publishing our journal (figure 1). BASEM is the leading multidisciplinary sport and exercise medicine membership organisation in the UK with a core responsibility to provide relevant, high-quality education to all those involved in this specialty. Our members comprise doctors, physiotherapists, researchers, nurses, radiologists and podiatrists just to name a few, and we editors celebrate this diverse background and experience with our choice of papers.

\section{A FOCUS ON ELITE SPORT AND EXERCISE MEDICINE}

For those physiotherapists, doctors and physiologists working within elite sport and exercise medicine there is plenty to read. Aspetar's Professor Sebastien Racinais et al broach the question as to whether athletes should be tested in the heat before a competition where the climate during the competition is likely to be hot (see page 700). This is the first in a series of short tips in BJSM on preparing athletes for the heat ahead of Tokyo 2021. The answer seems to be an unequivocal yes! Training in the heat prior to a competition allows heat acclimatisation and improves athlete's health and performance.

While you can't watch football live as we write, we can discuss the medicine of elite football. Dr Alejandro LópezValencian, from the University Miguel Hernández in the beautiful Alicante region of Spain, shares his comprehensive

\footnotetext{
${ }^{1}$ British Association of Sport and Exercise Medicine, Doncaster, UK

${ }^{2}$ West Ham United FC, London, UK

${ }^{3}$ Panacea Health, London, UK

${ }^{4}$ Sport \& Exercise Medicine, Stanford Hall, Defence \& National Rehabilitation Centre, Loughborough, UK
}

Correspondence to Dr Robin Chatterjee, British Association of Sport and Exercise Medicine, Doncaster DN9 3QS, UK; sportsdocrob@panacea-health.co.uk

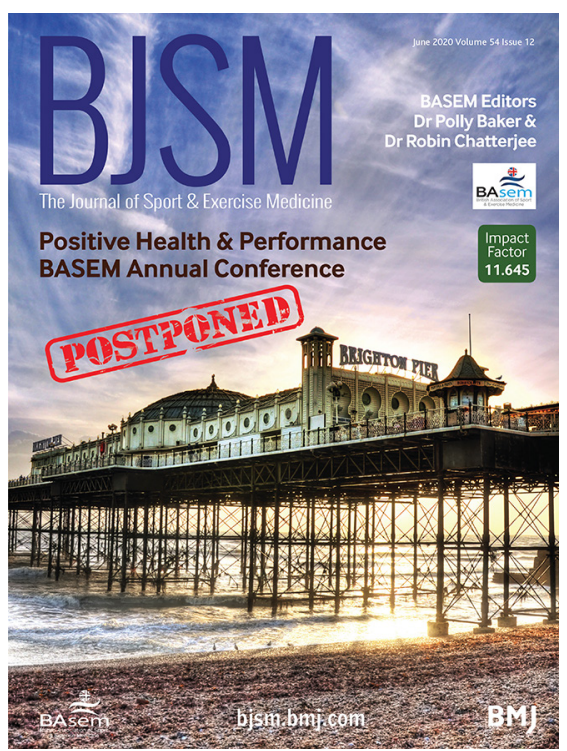

Figure 1 As we go to press, British Association of Sport and Exercise Medicine is considering the options for 2020 events and our schedule for 2021.

systematic review and meta-analysis of the epidemiology of professional football. Using time loss from training or match play as the key outcome (see page 711), the authors report the high incidence of injury among male professional football players and make a strong case for prevention strategies. This nicely leads on to the prospective study authored by Southampton's First Team Sports Scientist Dr Laura Bowen and her team, which examines the relationship between the acute versus chronic workload ratio and injury rate (see page 731 ). This has been a topic of much discussion! The authors suggest teams monitor workload carefully using this ratio aiming to prevent or minimise spikes.

BJSM has been the home for many papers by the world's leading sports cardiologists. In this issue, you can read that the 2017 European Society of Cardiologists recommendations for ECG interpretation in adolescent white and black soccer players held up under careful scrutiny and appear to be more effective than previous methods of ECG interpretation (see page 739).
BASEM supports BJSM in embracing the voice of patients. Read about the challenges faced by elite sportsmen and women when they retire from sport. $\mathrm{Mr}$ Patrick Dawson is brutally honest in his informative account of going from hero to zero in the sport of judo (see page 755).

\section{WE ARE ALSO EXPERTS IN}

\section{MUSCULOSKELETAL MEDICINE-NOT} SPORT ALONE!

A major component of sport and exercise medicine-musculoskeletal medicine-is the bread and butter for the majority of our membership. Peripatetic professor Peter O'Sullivan et al give us their top 10 facts on back pain (see page 698). Great value for those managing back pain such as sport and exercise medicine consultants, physiotherapists, GPs in sports medicine and exercise rehabilitation instructors.

Alongside back pain, osteoarthritis contributes substantially to the burden of disease in our community and if clinicians understand risk factors, we can educate and counsel those affected to better manage their condition. Sweden's Dr Barbara Snoeker et al's data (see page 725) illustrate the increased risk associated with specific structures that are affected in the label 'acute knee injuries'. ACL injury provides twice as much risk as a meniscal injury for long-term knee osteoarthritis. Ouch! (We are sorry about that!)

\section{METHODOLOGY \& STATISTICS}

Also in this issue, we highlight statistics and research methods and how they influence results-and ultimately, how we practice (see page 750). The quality of research within sport and exercise medicine and sports physiotherapy is increasing rapidly, and one reason for this is better data interpretation, more advanced methods and clearly stated hypotheses. All members of the multidisciplinary membership can learn from these papers that are written with us in mind.

Usually we would be promoting our annual conference, and as this issue goes to press, we fear that we have to postpone the planned BASEM 2020 conference. That should not stop our learning, and actually this type of event may strengthen us for the future-in ways such as our embracing video methods. Who has not become better at flipping between systems? As experts in physical activity, let's all keep providing inventive 


\section{Warm up}

and accessible ways to exercise when restricted at home. Exercise is even more critical at a time when people's anxiety has escalated. Keeping with our UK highlights, here is Edinburgh's professor Nanette Mutrie (@NanetteMutrie) on a free BJSM podcast: http://ow.ly/ FosF50zbsxm. It is our duty to help the world with physical activity in the time of COVID-19.

Twitter Robin Chatterjee @sportsdocrob and Polly Baker@drpollybaker
Contributors The intro has been wholly written by $\mathrm{RC}$ and $\mathrm{PB}$.

A) Check for updates

Funding The authors have not declared a specific grant for this research from any funding agency in the public, commercial or not-for-profit sectors.

Competing interests None declared.

Patient consent for publication Not required.

Provenance and peer review Commissioned; internally peer reviewed.

(c) Author(s) (or their employer(s)) 2020. No commercial re-use. See rights and permissions. Published by BMJ. 